\title{
Dry-gel synthesis of shaped transition-metal-doped M-MFI (M=Ti, Fe, Cr, Ni) zeolites by using metal-occluded zeolite seed sol as a directing agent
}

Hao Zhang, Yan Fei Fan, Yi Hong Huan, Ming Bo Yue*

Key Laboratory of Life-Organic Analysis, School of Chemistry and Chemical Engineering, Qufu Normal University, Shandong, China; Tel: 0086-537-4458301; fax: 0086-537-4456301; E-mail: mingboyue@126.com

\begin{abstract}
Shaped transition-metal-doped M-MFI zeolites were prepared using a rapid dry-gel conversion technique from shaped extrudates by using a metal-occluded zeolite seed sol as a directing agent. The metal ( $\mathrm{Ti}, \mathrm{Fe}, \mathrm{Cr}, \mathrm{Ni}$ )-occluded zeolites seed sols were prepared at a high tetrapropylammonium hydroxide (TPAOH)/SiO 2 molar ratio or with the addition of triethanolamine to keep a good dispersion of the transition metal in the seed sols. The silica gel and zeolites seed sols were mixed well and extruded into cylindrical-shaped extrudates with a diameter of $2 \mathrm{~mm}$ with the aid of polydimethylsiloxane (PDMS). The PDMS not only facilities the extrusion of the precursor but also increases the compressive strength of the obtained shaped zeolites. The metal-occluded seed sol promoted the distribution of the metal and provided crystal nuclei for rapid crystallization. In this method, the total molar ratio of $\mathrm{TPAOH} / \mathrm{SiO}_{2}$ decreased to $0.1-0.175$, which lowers the cost of preparing the zeolites. The morphology and textural properties were characterized by scanning electron microscopy and nitrogen sorption isotherms. The obtained shaped M-MFI zeolites comprised nanosized crystals (50-200 nm) and exhibited a good dispersion of the metals in the framework of the zeolite.
\end{abstract}

Keywords: Transition-metal-doped M-MFI zeolites; Dry-gel conversion; Shaped zeolites; Metal-occluded seed sol 


\section{Introduction}

Zeolites with an MFI topology possess intricate micropores and have had widespread use in industry such as adsorbents, separation media and shape selective catalysis [1-4]. Since Taramasso and co-workers discovered titanosilicate-1 (TS-1) zeolites in 1983 [5], transition metal isomorphously substituted zeolites with an MFI-type structure have been widely explored owing to their good selective oxidation redox properties under mild conditions [6-14].

In general, there are two strategies to transport the isolated transition metal atoms into the zeolite framework. One method is the so-called solvothermal synthesis, which requires large amounts of solvents such as alcohols $[15,16]$ or water $[17,18]$ at a high alkalinity. The high usage of alkali and solvents not only results in higher costs but also increases the environmental emissions during the filtration and washing process. Although the presence of solvents can ensure efficient transport of the metal atoms in the process of zeolite crystallization, the occupation of the autoclave space by solvents results in lower yields of the zeolites in the same available space. Another method is isomorphous substitution of metal atoms into the cavities of the zeolites by chemical vapor deposition $[19,20]$. In this method, a high-temperature calcination or steam treatment is necessary for the introduction of metal atoms into the silicate matrix [21-23].

To overcome these issues, Schüth's group and Xu's group successfully developed dry-gel conversion (DGC) methods [24,25] and this DGC methods have been applied to synthesis various materials, such as shaped ZSM-5 zeolites [26-27], Ti-beta zeolites [28-30], organic-inorganic hybrid MOR zeolites [31-33]. More recently, Xiao's group reported a solvent-free route for the synthesis of zeolites $[7,11,34]$. This solvent-free method has the advantage of increasing zeolite yields and reducing polluted wastes. The only disadvantage could be that this method requires $\mathrm{NH}_{4} \mathrm{~F}$ or $\mathrm{NH}_{4} \mathrm{Cl}$ as a 
mineralizing agent in the process of crystallization. The use of $\mathrm{NH}_{4} \mathrm{~F}$ not only increases the size of crystals but also limits the industrial production of zeolites at a large scale because of its toxicity to the environment. Therefore, it would be exciting if transition-metal-doped MFI zeolites could be prepared by a dry-gel conversion method at a lower alkalinity and using a minimal amount of solvents.

In this work, we use a one-step dry-gel conversion method to prepare shaped metal-doped MFI zeolites by using a low amount of TPAOH and minimal solvent. As shown in Scheme 1, the metal-doped zeolites seed sol was prepared at a high $\mathrm{TPAOH} / \mathrm{SiO}_{2}$ ratio. The obtained zeolites seed sol was used as a binder to extrude the silica gel into the shaped precursor and the shaped M-MFI (M=Ti, Fe, $\mathrm{Cr}, \mathrm{Ni}$ ) zeolites were obtained by dry-gel transformation from the shaped precursor.

\section{Experimental section}

\subsection{Shaped zeolite preparation}

The chemicals used in this work were sourced commercially and used without further purification. Tetrapropylammonium hydroxide (TPAOH, 25\% solution) was purchased from Shanghai Cainorise Chemicals Co., Ltd. Tetraethyl orthosilicate (TEOS, AR grade), titanium tetrabutoxide (TBOT, AR grade), ferric nitrate $\left(\mathrm{Fe}\left(\mathrm{NO}_{3}\right)_{3} \cdot 9 \mathrm{H}_{2} \mathrm{O}\right)$, nickel nitrate $\left(\mathrm{Ni}\left(\mathrm{NO}_{3}\right)_{2} \cdot 6 \mathrm{H}_{2} \mathrm{O}\right)$, chromium nitrate $\left(\mathrm{Cr}\left(\mathrm{NO}_{3}\right)_{3} \cdot 9 \mathrm{H}_{2} \mathrm{O}\right)$, polydimethylsiloxane (PDMS) and triethanolamine (TEA) were purchased from Sinopharm Chemical Reagent Co., Ltd. The silica gel (99.8 wt.\% $\mathrm{SiO}_{2}$, Aerosil 380) was purchased from the Shanghai King Chemical Co., Ltd.

The Ti-doped zeolites seed sol was prepared by mixing TPAOH, TEOS, TBOT and distilled water using the following molar composition: $\mathrm{TPAOH} / \mathrm{SiO}_{2} / \mathrm{TiO}_{2} / \mathrm{H}_{2} \mathrm{O}=0.35: 1: 0.0875: 20$. A typical procedure for the preparation of the seed sol was as follows: $7.84 \mathrm{~g}$ of TBOT was added dropwise into $75.0 \mathrm{~g}$ TPAOH water solution $(25 \%)$ and stirred at $0{ }^{\circ} \mathrm{C}$ for $60 \mathrm{~min}$, and then $54.8 \mathrm{~g}$ of TEOS was added under 
continuous stirring. After stirring at room temperature for $10 \mathrm{~h}$, the alcohols were removed repeatedly at $60{ }^{\circ} \mathrm{C}$ (sometimes, a small amount of water was added in this process to maintain the water volume). The mixture was transferred into a Teflon-lined autoclave and heated at $80{ }^{\circ} \mathrm{C}$ in an oven for $24 \mathrm{~h}$ to obtain the Ti-doped zeolites seed sol. The other three metal ( $\mathrm{M}=\mathrm{Fe}, \mathrm{Cr}, \mathrm{Ni})$-doped zeolites seed sols were prepared with the following molar composition: TPAOH $/ \mathrm{SiO}_{2} /$ metal nitrates/TEA/ $\mathrm{H}_{2} \mathrm{O}$ of $x: 1: 0.0875: 0.0875: 20$ (Fe and $\mathrm{Cr}, x=0.6125 ; \mathrm{Ni}, x=0.35)$. The procedures were similar to that of Ti-MFI seed sol besides the addition of TEA in the mixture. The TEA and metal nitrate were added into the deionized water, and then the mixture was added dropwise into the TPAOH solution, similar to the process used to prepare the Ti-MFI seed sol.

The shaped M-MFI zeolites were prepared as follows: the obtained M-MFI seed sol was mixed with a calculated amount of silica gel and PDMS under stirring. The mixture was mixed uniformly to form a gel and extruded into cylindrical shaped extrudates with a diameter of $2 \mathrm{~mm}$. The molar composition of the Ti-MFI extrudates was $\mathrm{TPAOH} / \mathrm{SiO}_{2} / \mathrm{TiO}_{2} / \mathrm{PDMS}=0.1: 1: 0.025: x(x=0,0.012,0.024$ and 0.036$)$. The other three M-MFI zeolites were prepared in the same way with the following molar composition: $\mathrm{TPAOH} / \mathrm{SiO}_{2} /$ metal nitrates/TEA $=x: 1: 0.025: 0.025(\mathrm{Fe}$ and $\mathrm{Cr} x=0.175 ; \mathrm{Ni} x=0.1)$. The obtained extrudates were transferred into Teflon-lined autoclaves and heated at $175{ }^{\circ} \mathrm{C}$ for different times. The autoclaves were then quenched in cold water and the product was dried at $80{ }^{\circ} \mathrm{C}$ overnight and calcined at $550{ }^{\circ} \mathrm{C}$ for $6 \mathrm{~h}$ to completely remove the organic template.

For an evaluation of the water content to the crystallization of zeolites, a series of Ti-MFIs were prepared with different amounts of water by using a molar composition of $\mathrm{TPAOH} / \mathrm{SiO}_{2} / \mathrm{TiO}_{2} / \mathrm{PDMS} / \mathrm{H}_{2} \mathrm{O}=0.1: 1: 0.025: x(x=2.5 \%, 5 \%, 10 \%)$, where $x$ denotes the weight percent of water added to the dried extrudates. Before addition of the water, the extrudates were dried at 
$60{ }^{\circ} \mathrm{C}$ for $12 \mathrm{~h}$. The obtained Ti-MFI sample was denoted as Ti-x-yh, where $\mathrm{x}$ is the molar ratio of $\mathrm{PDMS} / \mathrm{SiO}_{2}$ in the extrudates and $\mathrm{y}$ is the crystallization time. For comparison, conventional TS-1 catalyst was prepared through hydrothermal method reported by M.G. Clerici and G. Bellussi [35]. The other three transition-metal-doped zeolites were obtained after $48 \mathrm{~h}$ crystallization and were denoted as Fe-MFI, Ni-MFI and Cr-MFI, respectively.

\subsection{Characterization}

The X-ray diffraction (XRD) measurements were collected on a Rigaku-MiniFlex 600 diffractometer using $\mathrm{Cu} \mathrm{K} \alpha$ radiation and a nickel filter in the $2 \theta$ angle range from $5^{\circ}$ to $35^{\circ}$ at $35 \mathrm{kV}$ and $25 \mathrm{~mA}$. The relative crystallinity was estimated by comparing the five peaks areas $\left(22-28^{\circ}\right)$ of these samples with those peaks areas of TS-1zeolite, which was prepared through method reported by M.G. Clerici and G. Bellussi [35]. Infrared spectroscopy was performed on a Fourier-transform infrared (FTIR) spectrometer (NEXUS 670) in the range 400-4000 $\mathrm{cm}^{-1}$ using the conventional $\mathrm{KBr}$ wafer technique. Scanning electron microscopy (SEM) experiments were performed on a Hitachi S-4800 electron microscope with an acceleration voltage of $3 \mathrm{kV}$. Ultraviolet-visible (UV-vis) spectra were performed on a Shimadzu UV-2400PC using the diffuse reflectance mode with $\mathrm{BaSO}_{4}$ as a reference. Nitrogen adsorption-desorption isotherms were performed at $-196{ }^{\circ} \mathrm{C}$ using a Quantachrome Autosorb-3B volumetric adsorption analyzer. The samples were outgassed at $300{ }^{\circ} \mathrm{C}$ for $4 \mathrm{~h}$ before the adsorption measurements. The BET specific surface areas were calculated using adsorption data acquired at a relative pressure $\left(\mathrm{p} / \mathrm{p}_{0}\right)$ range of $0.05-0.22$. The micropore and external surface areas as well as the micropore volume were calculated by the t-plot method. Thermogravimetric (TG) and derivative thermogravimetric (DTG) analyses were performed using a PerkinElmer TGA analyzer with a heating

rate of $10{ }^{\circ} \mathrm{C} \min ^{-1}$ from 25 to $800{ }^{\circ} \mathrm{C}$ under an air flow. The diametral compressive strength was 
obtained on a DL3 particle strength tester (Dalian Penghui Science and Technology Co., Ltd).

\subsection{Catalytic reactions}

The epoxidation of 1-hexene were carried out in a $50 \mathrm{ml}$ three necked flask fitted with a condenser. $0.05 \mathrm{~g}$ of catalyst, $10 \mathrm{ml}$ of methanol, $10 \mathrm{mmol}$ of 1-hexene and $10 \mathrm{mmol} \mathrm{H}_{2} \mathrm{O}_{2}(30 \mathrm{wt} \%$ solutions $)$ were successively charged into the reactor [36]. The reaction was carried out under vigorous stirring and the temperature was controlled at $60{ }^{\circ} \mathrm{C}$ with an oil bath for $2 \mathrm{~h}$. After the reaction, the reactants were cooled quickly, and $0.5 \mathrm{~g}$ cyclohexanone (internal standard) was added to the flask and stirred for $1 \mathrm{~min}$. After removal of the catalyst powder, the reaction mixture was analyzed using a gas chromatograph (capillary column, FID detector) with cyclohexanone as the internal standard.

\section{Results and Discussion}

Fig. 1A shows the XRD pattern and FTIR spectrum of the Ti-0.024-yh series samples obtained with a molar ratio $\mathrm{PDMS} / \mathrm{SiO}_{2}=0.024$. As shown in Fig. $1 \mathrm{~A}$, the wide dispersive peak of amorphous titanosilicate at $15-30^{\circ}$ disappears after $8 \mathrm{~h}$ crystallization and the diffraction peaks of MFI type zeolite appear after $12 \mathrm{~h}$ crystallization. The relative crystallinity of Ti-0.024-48h sample reaches $90 \%$, indicating the successful transformation from amorphous silica to MFI zeolite structure within $48 \mathrm{~h}$ [36]. The FTIR spectrum of these samples (Fig. 1B) also confirmed these transformations. The band at 550 $\mathrm{cm}^{-1}$ is mainly attributed to the MFI zeolites with double five-membered rings [37]. The intensity ratio of the 550 and $450 \mathrm{~cm}^{-1}$ band is used to assess the formation of MFI zeolite and is termed the FTIR crystallinity. As the band at $550 \mathrm{~cm}^{-1}$ becomes stronger with increasing crystallization time, the increasing intensity ratio between the 550 and $450 \mathrm{~cm}^{-1}$ peaks proves the increasing crystallinity of the samples, which is in good agreement with the variation trend of the XRD. The results illustrate that shaped TS-1 zeolites with good crystallinity can be synthesized with low TPAOH usage 
(TPAOH: $\mathrm{SiO}_{2}=0.1$ ) using this strategy.

Fig. 2 shows the XRD patterns and FTIR spectra of the Ti-X-48h series samples, prepared with the addition of different amounts of PDMA. As shown in Fig. 2A, the typical XRD peaks of MFI-type zeolite can be clearly observed. The FTIR spectrum also shows the band at $550 \mathrm{~cm}^{-1}$, which is attributed to double five-membered rings of the MFI zeolites (Fig. 2B). These characterization results prove that the Ti-doped MFI zeolites can be prepared by this strategy using a small amount of TPAOH and minimal water with the addition of PDMS. However, the relative crystallinity of the obtained Ti-MFI zeolites decreases slightly with increasing PDMS content. Compared with the TS-1 sample (synthesized by hydrothermal method), the relative crystallinity of Ti-x-48h $(\mathrm{x}=0.0,0.012,0.024,0.036)$ samples are 100\%, 99\%, 98\%, 96\% respectively. The PDMS has two methyl groups and displays high hydrophobic properties. In the crystallization process, the TPAOH and water play an important role on the hydrolysis and condensation of $\mathrm{Si}-\mathrm{O}-\mathrm{Si}$ and $\mathrm{Ti}-\mathrm{O}-\mathrm{Si}$ during the crystallization process by offering a suitable alkalinity for the solid transformation. Owning to its hydrophobic features, PDMS prevents TPAOH and water transmission in the solid precursor, which retards the crystallization of the zeolites. Therefore, the addition of PDMS retarded the crystallization of zeolites. However, the initial cylindrical shape of the metal-silicate extrudates was well maintained during the crystallization process (Fig. S1), and the final products possessed excellent mechanical strength. Especially, the diametral compressive strength of the obtained shaped zeolites is enhanced with increasing addition of PDMS. In the extrusion process, the addition of the PDMS made the precursor mixture maintain ductility and favored the extrusion molding. Without addition of the PDMS, there were lots of cracks in the surface of Ti-0-yh extrudates. When the PDMS was added, the surface of the obtained Ti-x $(x=0.012,0.024,0.036)$ series cylindrical-shaped extrudates became smooth. So, the PDMS performed as the lubricants and binders to favor the shaping 
of the extrudates, which increased the compressive strength of the obtained shaped zeolites. As shown of Table 1, the diametral compressive strength of the TS-0-48h sample is only $32.0 \mathrm{~N} \mathrm{~cm}^{-1}$. The diametral compressive strength of TS-0.012-48h, TS-0.024-48h and TS-0.036-48h sample is 53.8, $94.899 .9 \mathrm{~N}$ $\mathrm{cm}^{-1}$, respectively. Considering both the diametral compressive strength and the relative crystallinity comprehensively, the TS-0.024-48h sample would be more profitable for the industry application. Therefore, the optimum hybrid molar ratio of $\mathrm{PDMS}$ to $\mathrm{SiO}_{2}$ is fixed to 0.024 .

To reduce the impact of the PDMS on the crystallization process, the addition of more water would be favorable. Fig. 3 shows the influence of water content on the crystallinity of zeolites prepared with a different amount of PDMS. As shown by the XRD patterns, the Ti-0-yh series samples achieve high crystallinity with $5 \mathrm{wt} \%$ water within $48 \mathrm{~h}$. For the Ti-0.036 series samples, the diffraction peaks of the amorphous titanosilicate are retained after $48 \mathrm{~h}$ crystallization with 5 wt $\%$ water addition. The TS-0.036 sample achieves high crystallinity when the water content is increased to $10 \mathrm{wt} \%$ (Fig. 3). The same phenomenon is observed for the TS-0.012 and TS-0.024 series sample (Fig. S2). Therefore, 10\% weight percent of water is needed for the TS-0.012 and TS- 0.024 series samples. This amount of water is required for the synthesis of zeolites by solid interaction, which is needed for hydrolysis and condensation of $\mathrm{Si}-\mathrm{O}-\mathrm{Si}$ and/or $\mathrm{Ti}-\mathrm{O}-\mathrm{Si}$ bonds during the crystallization processes $[7,11,34]$.

The TG and DTG curves of the Ti-x-yh samples are shown in Fig. 4A and B, respectively. As shown in Fig. 4A, the TG curve can be divided into three zones. The weight loss in zone $\mathrm{I}\left(30-100{ }^{\circ} \mathrm{C}\right)$ is attributed to the removal of physisorbed water. The weight loss in zone II $\left(100-300{ }^{\circ} \mathrm{C}\right)$ is attributed to the thermal decomposition of the structure-directing agent (TPAOH) on the surface or/and amorphous titanosilicate gels. The weight loss in zone III $\left(300-800{ }^{\circ} \mathrm{C}\right)$ is associated with the thermal decomposition of the structure directing agent $\left(\mathrm{TPA}^{+}\right)$in the micropores of the samples. The Ti-0.024-0h 
and Ti-0-0h show distinct physisorbed water weight loss before $100{ }^{\circ} \mathrm{C}$, and this water was necessary for the crystallization processes, as discussed above (Fig. 3 and Fig. S2) [11,34]. The TPAOH weight loss was in Zone II $\left(100-300{ }^{\circ} \mathrm{C}\right)$, which is in agreement with the amorphous state of these two samples. After crystallization for $48 \mathrm{~h}$, these four Ti-X-48h series samples show distinct weight loss in zone III $\left(300-800^{\circ} \mathrm{C}\right.$ ), and this loss can be attributed to the TPAOH that is occluded into the micropores of the formed zeolite during the crystallization process. [38]

The Ti coordination states of the obtained Ti-MFI zeolites were investigated by UV-vis spectroscopy (Fig. 5). The Ti-X-48h samples obtained using different amounts of PDMS show similar results: the band at $210 \mathrm{~nm}$ was attributed to ligand-to-metal charge transfer associated with the isolated Ti(IV) framework sites in tetrahedral coordination; octahedral Ti $(260 \mathrm{~nm})$ and anatase $(330 \mathrm{~nm})$ are hardly observed. [39] The UV spectra of these two amorphous samples (Ti-0.024-4h and Ti-0.036-4h) are displayed in Fig. 5 (sample $\mathrm{c}$ and e). And these two samples show the same UV spectra as the TS-0.036-48h besides weak band at $260 \mathrm{~nm}$, which means that most of Ti species have occupied isolated Ti(IV) framework sites in the early period during the crystallization process. With increasing crystallization time, this extra-framework titanium progressively enters the framework of the zeolites with tetrahedral coordination.

Fig. 6 shows $\mathrm{N}_{2}$ sorption isotherms of the samples. These four TS-X-48h series samples exhibit a steep increase at a low relative pressure $10^{-6}<\mathrm{p} / \mathrm{p}_{0}<0.01$, which is typical for microporous materials [40]. The surface areas of these four TS-X-48h series samples are around $400 \mathrm{~m}^{2} \mathrm{~g}^{-1}$, which is in agreement with the similar relative crystallinity of these samples (around 98\%). For well illustration of the textural property of these shaped extrudates, the $\mathrm{N}_{2}$ sorption isotherms of the Ti-x-0h $(\mathrm{x}=0,0.036)$ samples are shown in the Fig. 7. The Ti-0-0h and Ti-0.036-0h sample exhibited type-IV isotherms with a hysteresis 
loop. The surface area of the Ti-0-0h and Ti-0.036-0h samples are 627 and $662 \mathrm{~m}^{2} \mathrm{~g}^{-1}$ respectively, which is much higher than the raw material silica gel. The reason may be ascribed that $23 \mathrm{wt} . \%$ silica source in the Ti-0-0h and Ti-0.036-0h samples come from the zeolite seed sol. After crystallization for $48 \mathrm{~h}$, a hysteresis loop also can be observed at a relative pressure of $0.7-0.98$ in these four TS-x-48h series samples (Fig. 6), which indicates that there are mesoporous pores in these samples. [41] The mesoporous pores would come from aggregation of primary nanozeolite crystals. Fig. 8 shows the SEM images of these samples obtained with different addition of PDMS. The crystal size of these four samples is about $100 \mathrm{~nm}$. The BET surface area and the micropore volume of TS- $\mathrm{x}-48 \mathrm{~h}(\mathrm{x}=0,0.012$, $0.024,0.036)$ are $466,478,459,479 \mathrm{~m}^{2} \mathrm{~g}^{-1}$ and $0.18,0.18,0.17,0.18 \mathrm{~cm}^{3} \mathrm{~g}^{-1}$, respectively, which are similar with the TS-1 synthesized by the hydrothermal method. [35,42]

To survey the catalytic capacity of the resulted Ti-MFI zeolites, epoxidation of 1-hexene by using $\mathrm{H}_{2} \mathrm{O}_{2}$ as oxidant was used as probe reaction. As shown of Table 1, the catalytic activity of these four samples is similar. The 1-hexene conversion of these samples with methanol as solvent is around $20 \%$ and the epoxide selectivity is around $90 \%$, which is similar as the catalytic oxidation performance of conventional TS-1 zeolites [42]. When the acetonitrile were used as solvents to test the catalytic ability of the obtained TS-1 zeolites, the 1-hexene conversion of these samples decreased to $16 \%$ and the epoxide selectivity increased to $96 \%$. This result is in agreement with the results reported in the literature [43]. Compared with the acetonitrile, methanol as a solvent favors the oxidation of alkenes with TS-1, due to the hydrophobic character of TS-1 zeolites [43]. With increasing addition of PDMS, the oxidation activity of the obtained zeolites decreases slightly. The reason could attribute to the lower crystallinity and lower Ti/Si molar ratio in the resulted zeolites owning to more addition of PDMS. In conclusion, the Ti-MFI zeolites synthesized through this dry-gel conversion method owns similar 
catalytic oxidation performance as that of conventional TS-1 zeolites.

This strategy has been extended to successfully synthesize other transition-metal-doped zeolites M-MFI (M=Fe, Ni, Cr) with an MFI structure. Fig. 9A shows XRD pattern of M-MFI (M=Fe, Ni, Cr), which are typical of MFI-type zeolite structures. These three samples also exhibit typical $\mathrm{N}_{2}$ sorption isotherms (Fig. 9B) of microporous materials with an abrupt increase at low relative pressure $10^{-6}<\mathrm{p} / \mathrm{p}_{0}<0.01$. In addition, there are hysteresis loops at a higher relative pressure. In particular, the Fe-MFI sample exhibits a H4 type hysteresis loop in the relative pressure range p/p0 (0.7-0.9), which indicates the existence of mesoporous pores. Fig. 10 shows the SEM images of M-MFI (M=Fe, Ni, Cr). The morphology of Cr-MFI is similar with the Ti-MFI sample above and is composed of 50 nm crystals. The size of the Ni-MFI is around 100 to $300 \mathrm{~nm}$, which is larger than Cr-MFI. The Fe-MFI sample is composed of $1 \mu \mathrm{m}$ spheres aggregated with $200 \mathrm{~nm}$ sticklike crystals. The mesoporous pore is built by the aggregation of these sticklike nano-crystals. As illustrated in table 2, the BET surface area and micropore volume of M-MFI (M=Fe, Ni, Cr) are 397, 408, $422 \mathrm{~m}^{2} \mathrm{~g}^{-1}$ and $0.16,0.15,0.16 \mathrm{~cm}^{3} \mathrm{~g}^{-1}$, respectively.

The metal coordination state of the M-MFI zeolites was investigated by UV spectroscopy. As shown in Fig. 11, the Fe-MFI sample exhibited a typical absorption band centered at $225 \mathrm{~nm}$, which was assigned to the ligand-to-metal charge transfer bands between the $\mathrm{Fe}$ and $\mathrm{O}$ atoms of the $\mathrm{Fe}-\mathrm{O}-\mathrm{Si}$ species in the zeolite framework. [44,45] The Ni-MFI sample exhibited a strong absorption band at 200 nm, which was assigned to the ligand-to-metal charge transfer band of the Ni-O-Si species with tetrahedral coordination in the zeolite. [46] The Cr-MFI exhibited distinct absorption bands at approximately 270 and $370 \mathrm{~nm}$, which were assigned to the charge transfer from $\mathrm{O}^{2-}$ to $\mathrm{Cr}^{6+}$ of the tetrahedrally coordinated chromium oxide moieties. $[47,48]$ The absorption bands at $550 \mathrm{~nm}$, assigned to 
the absorption of the dichromate of $\mathrm{Cr}_{2} \mathrm{O}_{3}$ cluster, is hardly observed, indicating that there are seldom tetrahedrally coordinated chromium oxide moieties existed.

\section{Conclusions}

In general, shaped nanosized transition-metal-doped zeolites with an MFI-type structure has been successfully synthesized in a highly sustainable way. This strategy exhibits the following advantages: (1) low usage of the TPAOH and water: the amount of TPAOH and solvent has been reduced close the theoretically value, which not only cuts costs and but also reduces environmental pollution. (2) A significant reduction of the reaction pressure: there is no extra water added into the autoclave during the crystallization process, so the reaction pressure is greatly decreased. (3) Full utilization of the autoclave volume: compared with traditional hydrothermal synthesis, the dry-gel conversion method can be used to obtain more zeolite in one autoclave because the hydrothermal method needs lots of solvent, which occupies a large volume. (4) One step shaping: this strategy can produce the shaped zeolite in one step, which not only avoids a series of complicated processes but also enhances productivity in industrial application.

\section{Acknowledgements}

This work is supported by National Science Foundation of China (21003083) and Shandong

Provincial Natural Science Foundation (ZR2014BM012). M. B. Yue is thankful for the National Entrepreneurship Training Programs for Undergraduates (201510446058).

\section{Reference:}

[1] R. Mrad, A. Aissat, R. Cousin, D. Courcot, S. Siffert, Appl. Catal. A 504 (2015) 542-548.

[2] R. Khare, D. Millar, A. Bhan, J. Catal., 321 (2015) 23-31.

[3] Y. Jin, X. Chen, Q. Sun, N. Sheng, Y. Liu, C. Bian, F. Chen, X. Meng, F.-S. Xiao, Chem.-Eur. J. 20 
(2014) 17616-17623.

[4] X.J. Deng, Y. Wang, L. Shen, H.H. Wu, Y.M. Liu, M.Y. He, Ind. Eng. Chem. Res. 52 (2013) 1190-1196.

[5] M. Taramasso, G. Perego and B. Notari, US Patent 4410501, 1983.

[6] S. Li, A. Tuel, D. Laprune, F. Meunier, D. Farrusseng, Chem. Mater., 27 (2015) 276-282.

[7] Q.M. Wu, X. Wang, G.D. Qi, Q. Guo, S.X. Pan, X.J. Meng, J. Xu, F. Deng, F.T. Fan, Z.C. Feng, C. Li, S. Maurer, U. Müller, F.S. Xiao, J. Am. Chem. Soc. 136 (2014) 4019-4025.

[8] C.H. Lin, Y.C. Yang, C.Y. Chen, S.L. Wang, Chem. Mater., 18 (2006) 2095-2101.

[9] A. Ristić, K. Lázár, H. Solt, and V. Kaučič, CrystEngComm 13 (2011) 1946-1952.

[10] T. Selvam, and M.P. Vinod, Appl. Catal. A 134 (1996) L197-L201.

[11] L. Ren, Q. Wu, C. Yang, L. Zhu, C. Li, P. Zhang, H. Zhang, X. Meng, and F. Xiao, J. Am. Chem. Soc. 134 (2012) 15173-15176.

[12] Q. Yu, C. Li, X. Tang, and H. Yi, RSC Adv 5 (2015) 8152-8162.

[13] C. Hammond, M.M. Forde, M.H. Ab Rahim, A. Thetford, Q. He, R.L. Jenkins, N. Dimitratos, J.A. Lopez-Sanchez, N.F. Dummer, D.M. Murphy, A.F. Carley, S.H. Taylor, D.J. Willock, E.E. Stangland, J. Kang, H. Hagen, C.J. Kiely, and G.J. Hutchings, Angew. Chem. Int. Ed. 51 (2012) $5129-5133$.

[14] G. Centi, S. Perathoner, Catal. Today 143 (2009) 145-150.

[15] N. Kanno, M. Miyake, M. Sato, Zeolites 14 (1994) 625-628.

[16] R.E. Morris, S.J. Weigel, Chem. Soc. Rev. 26 (1997) 309-317.

[17]] D.P. Serrano, R. Sanz, P. Pizarro, I. Moreno, Top. Catal. 53 (2010) 1319-1329.

[18] H. Xin, J. Zhao, S. Xu, J. Li, W. Zhang, X. Guo, E.J.M. Hensen, Q. Yang, C. Li, J. Phys. Chem. C 
114 (2010) 6553-6559.

[19] K.S. Pillai, J. Jia, and W.M.H. Sachtler, Appl. Catal. A 264 (2004) 133-139.

[20] P. Marturano, L. Drozdová, A. Kogelbauer, R. Prins, J. Catal. 192 (2000) 236-247.

[21] G.D. Pirngruber, M. Luechinger, P.K. Roy, A. Cecchetto, and P. Smirniotis, J. Catal. 224 (2004) 429-440.

[22] H. Chen, and W.M.H. Sachtler, Catal. Today 42 (1998) 73-83.

[23] M. Romero-Sáez, D. Divakar, A. Aranzabal, J.R. González-Velasco, J.A. González-Marcos, Appl. Catal. B 180 (2016) 210-218.

[24] R. Althoff, K. Unger, F. Schüth, Microporous Mater. 2 (1994) 563-564.

[25] U. Deforth, K.K. Unger, F. Schüth, Microporous Mater. 9 (1997) 287-290.

[26] M.B. Yue, N. Yang, Y.M. Wang, Acta. Phys-Chim Sin. 28 (2012) 2115-2121.

[27] M.B. Yue, N. Yang, W.Q. Jiao, Y.M. Wang, M.Y. He, Solid State Sci. 20 (2013) 1-7.

[28] T. Tatsumi, Q. Xia, N. Jappar, Chem. Lett. 26 (1997) 677-678.

[29] Q.H. Xia, X. Chen, T. Tatsumi, J. Mol. Catal. A: Chem. 176 (2001) 179-193.

[30] Q.H. Xia, T. Tatsumi, Mater. Chem. Phys. 89 (2005) 89-98.

[31] D. Zhou, X. Lu, J. Xu, A. Yu, J. Li, F. Deng, Q. Xia, Chem. Mater., 24 (2012) 4160-4165.

[32] D. Zhou, J. Xu, J. Deng, X. Wei, X. Lu, X. Chu, F. Deng, Q. Xia, Dalton T. 44 (2015) 14732-14740.

[33] D. Zhou, X. Chu, J. Xu, T. Zhang, X. Lu, F. Deng, S. Wang, Q. Xia, Microporous Mesoporous Mater. 220 (2016) 225-230.

[34] X. Meng, and F. Xiao, Chem. Rev. 114 (2014) 1521-1543.

[35] M.G. Clerici, G. Bellussi, and U. Romano, J. Catal. 129 (1991) 159-167. 
[36] M.B. Yue, M.N. Sun, F. Xie, and D.D. Ren, Microporous Mesoporous Mater. 183 (2014) 177-184.

[37] J.C. Jansen, F.J. van der Gaag, and H. van Bekkum, Zeolites 4 (1984) 369-372.

[38] L.M. Parker, D.M. Bibby, and J.E. Patterson, Zeolites 4 (1984) 169-174.

[39] W. Zhang, M. Fröba, J. Wang, P.T. Tanev, J. Wong, and T.J. Pinnavaia, J. Am. Chem. Soc. 118 (1996) 9164-9171.

[40] R. Xu, W. Pang, J. Yu, Q. Huo, and J. Chen, Chemistry of Zeolites and Related Porous Materials. Wiley, Singapore, 2007.

[41] O. Sel, D. Kuang, M. Thommes, and B. Smarsly, Langmuir 22 (2006) 2311-2322.

[42] J. H. Zhang, M.B. Yue, X.N. Wang, and D. Qin, Microporous Mesoporous Mater. 217 (2015) 96-101.

[43] W. B. Fan, P. Wu, T. Tatsumi, J. Catal. 256 (2008) 62-73

[44] S. Bordiga, R. Buzzoni, F. Geobaldo, C. Lamberti, E. Giamello, A. Zecchina, G. Leofanti, G. Petrini, G. Tozzola, G. Vlaic, J. Catal. 158 (1996) 486-501.

[45]D. Guo, B. Shen, G. Qi, L. Zhao, J. Xu, F. Deng, Y. Qin, Q. Guo, S. Ren, X. Gao, S. Qin, B. Wang, H. Zhao, H. Liu, X. Pang, Chem. Commun. 50 (2014) 2660.

[46] X. Li, B. Li, H. Mao, and A.T. Shah, J. Colloid. Interf. Sci. 332 (2009) 444-450.

[47] S. Ohshiro, O. Chiyoda, K. Maekawa, Y. Masui, M. Anpo, H. Yamashita, Cr. Chim. 9 (2006) 846-850.

[48] E.P. Reddy, L. Davydov, P.G. Smirniotis, J. Phys. Chem. B 106 (2002) 3394-3401. 
Table 1 Textural property of the Ti-X-48h samples and the catalytic performances to the oxidation of 1-hexene

\begin{tabular}{|c|c|c|c|c|c|c|c|}
\hline \multirow[t]{2}{*}{ Sample } & \multirow{2}{*}{$\begin{array}{c}\mathrm{S}_{\mathrm{BET}} \\
\left(\mathrm{m}^{2} \mathrm{~g}^{-1}\right)\end{array}$} & \multirow{2}{*}{$\begin{array}{c}\mathrm{V}_{\text {micro }} \\
\left(\mathrm{cm}^{3} \mathrm{~g}^{-1}\right)\end{array}$} & \multirow{2}{*}{$\begin{array}{l}\text { Strength }^{\mathrm{a}} \\
\left(\mathrm{N} \mathrm{cm}^{-1}\right)\end{array}$} & \multicolumn{2}{|c|}{ Methanol $^{c}$} & \multicolumn{2}{|c|}{ Acetonitrile $^{c}$} \\
\hline & & & & Conv. & Selec. ${ }^{b}$ & Conv. & Selec. ${ }^{b}$ \\
\hline Ti-0-48h & 466 & 0.18 & 32.0 & 20.4 & 91 & 15.7 & 97 \\
\hline Ti-0.012-48h & 478 & 0.18 & 53.8 & 20.5 & 92 & 16.4 & 96 \\
\hline Ti-0.024-48h & 459 & 0.17 & 94.8 & 20.3 & 90 & 16.5 & 97 \\
\hline Ti-0.036-48h & 479 & 0.18 & 99.9 & 19.8 & 91 & 15.4 & 97 \\
\hline
\end{tabular}

a, Diametral compres-sive strength; b, Epoxide selectivity; c, the solvents used in the oxidation of 1-hexene. 
Table 2 Textural properties of M-MFI zeolites

\begin{tabular}{llll}
\hline Sample & $\begin{array}{l}\mathrm{S}_{\mathrm{BET}} \\
\left(\mathrm{m}^{2} \mathrm{~g}^{-1}\right)\end{array}$ & $\begin{array}{l}\mathrm{V}_{\text {micro }} \\
\left(\mathrm{cm}^{3} \mathrm{~g}^{-1}\right)\end{array}$ & $\begin{array}{l}\mathrm{V}_{\text {total }} \\
\left(\mathrm{cm}^{3} \mathrm{~g}^{-1}\right)\end{array}$ \\
\hline Fe-MFI & 397 & 0.16 & 0.41 \\
Ni-MFI & 408 & 0.15 & 0.53 \\
Cr-MFI & 422 & 0.16 & 0.56 \\
\hline
\end{tabular}




\section{Captions of Figures and Tables}

Table 1 Textural properties and catalytic performance of the Ti-X-48h samples

Table 2 Textural properties of M-MFI zeolites

Scheme 1 Schematic illustration of M-MFI zeolites preparation process.

Fig. 1 XRD patterns (A) and FTIR spectra (B) of Ti-0.024-yh samples with different crystallization times.

Fig. 2 XRD patterns (A) and Infrared spectra (B) of Ti-X-48h series samples: (a) TS-1, (b) Ti-0.0-48h, (c) Ti-0.012-48h, (d) Ti-0.024-48h, (e) Ti-0.036-48h.

Fig. 3 XRD patterns of Ti-X-48h series sample prepared with a different weight percent of water.

Fig. 4 TG (A) and DTG (B) curves of samples: (a) Ti-0.024-0h, (b) Ti-0-0h, (c) Ti-0-48h, (d) Ti-0.012-48h, (e) Ti-0.024-48h, (f) Ti-0.036-48h.

Fig. 5 UV-visible spectra of Ti-MFI zeolites: (a) Ti-0-48h, (b) Ti-0.012-48h, (c) Ti-0.024-4h, (d) Ti-0.024-48h, (e) Ti-0.036-4h, (f) Ti-0.036-48h.

Fig. 6. Nitrogen adsorption-desorption isotherms of the Ti-X-48h series sample: (a) Ti-0-48h, (b) Ti-0.012-48h, (c) Ti-0.024-4h, (d) Ti-0.024-48h. The isotherms of Ti-0.012-48h, Ti-0.024-48h and Ti-0.036-48h samples were offset vertically by 150,300 and $450 \mathrm{~cm}^{3} \mathrm{~g}^{-1}$, respectively.

Fig. 7. Nitrogen adsorption-desorption isotherms of the Ti-0-0h and Ti-0.036-0h sample. The isotherms of Ti-0.036-0h sample was offset vertically by $150 \mathrm{~cm}^{3} \mathrm{~g}^{-1}$.

Fig. 8 SEM images of the Ti-X-48h series sample.

Fig. 9 XRD patterns (A) and $\mathrm{N}_{2}$ sorption isotherms (B) of Ni-MFI, Cr-MFI, Fe-MFI samples.

Fig. 10 SEM images of the Ni-MFI, Cr-MFI and Fe-MFI samples.

Fig. 11 UV-visible spectra of the Ni-MFI, Cr-MFI and Fe-MFI samples. 


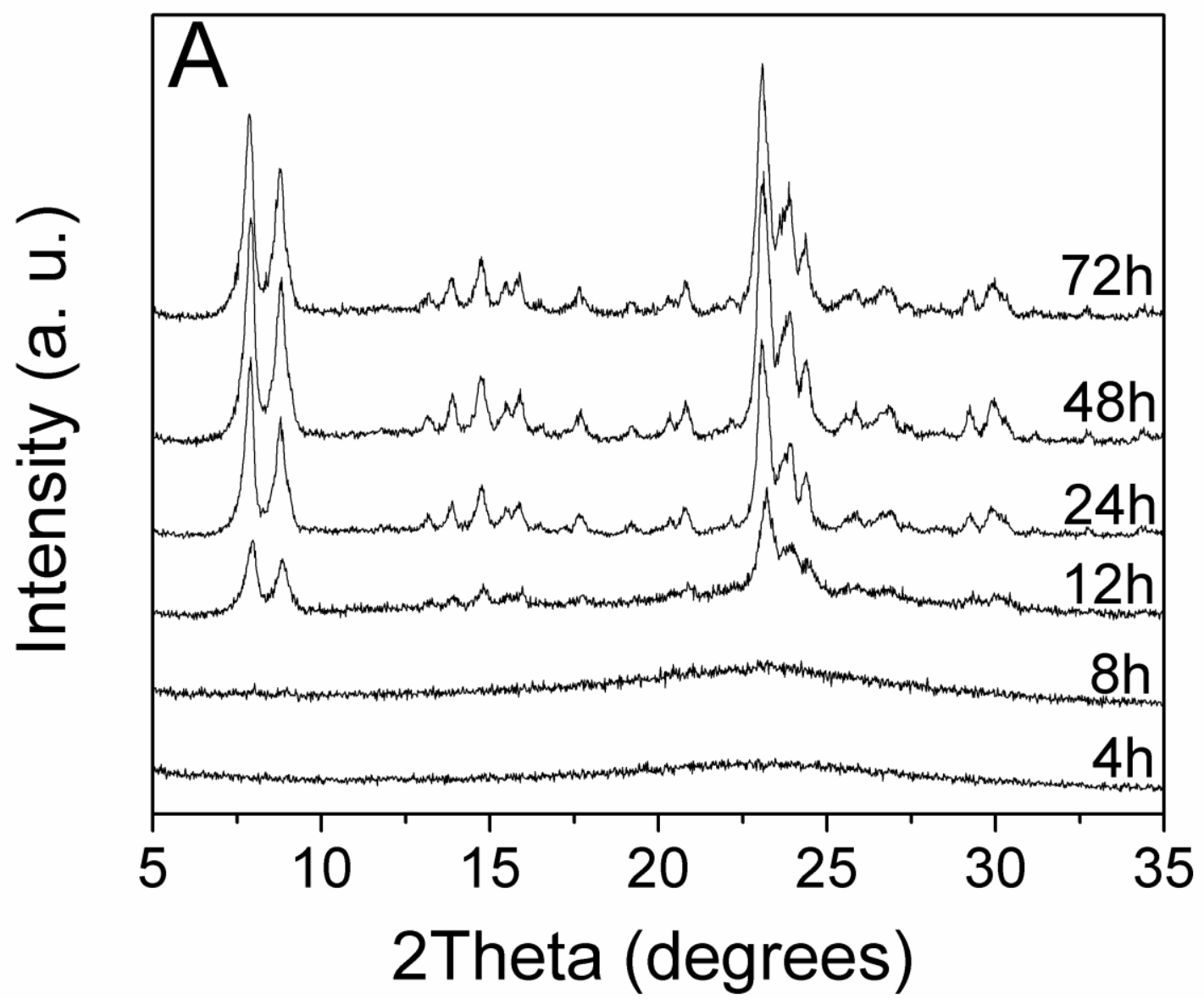




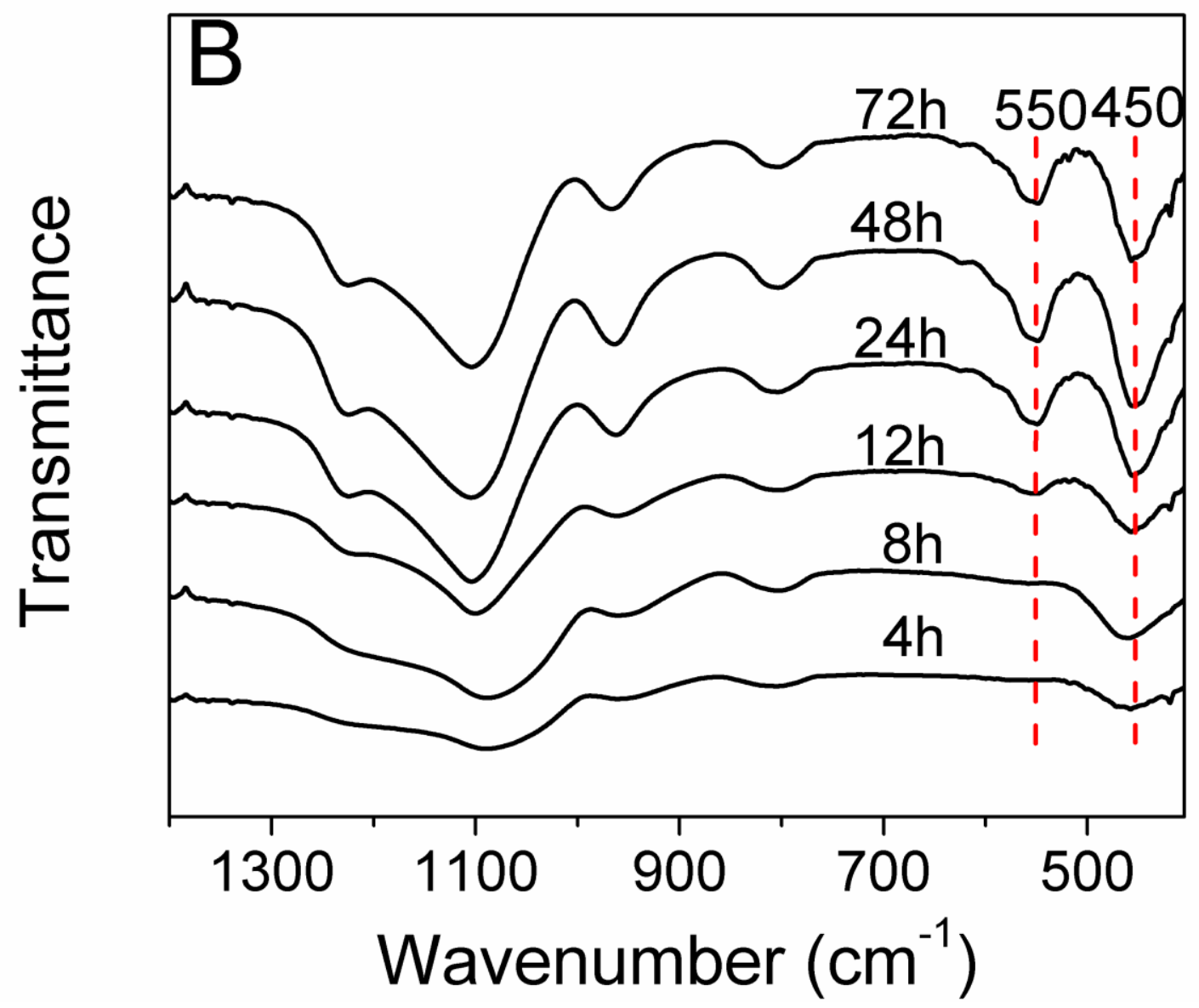




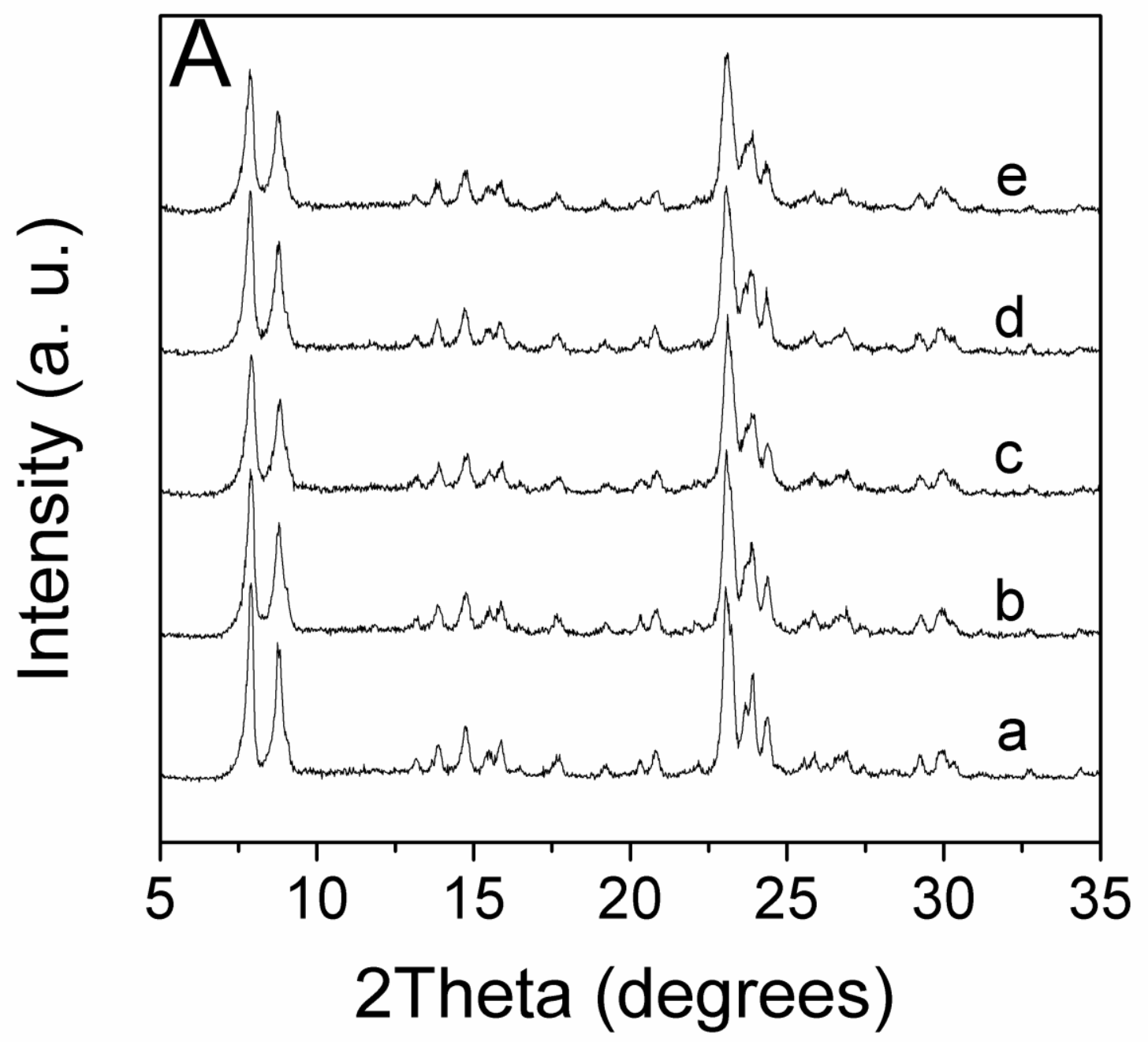




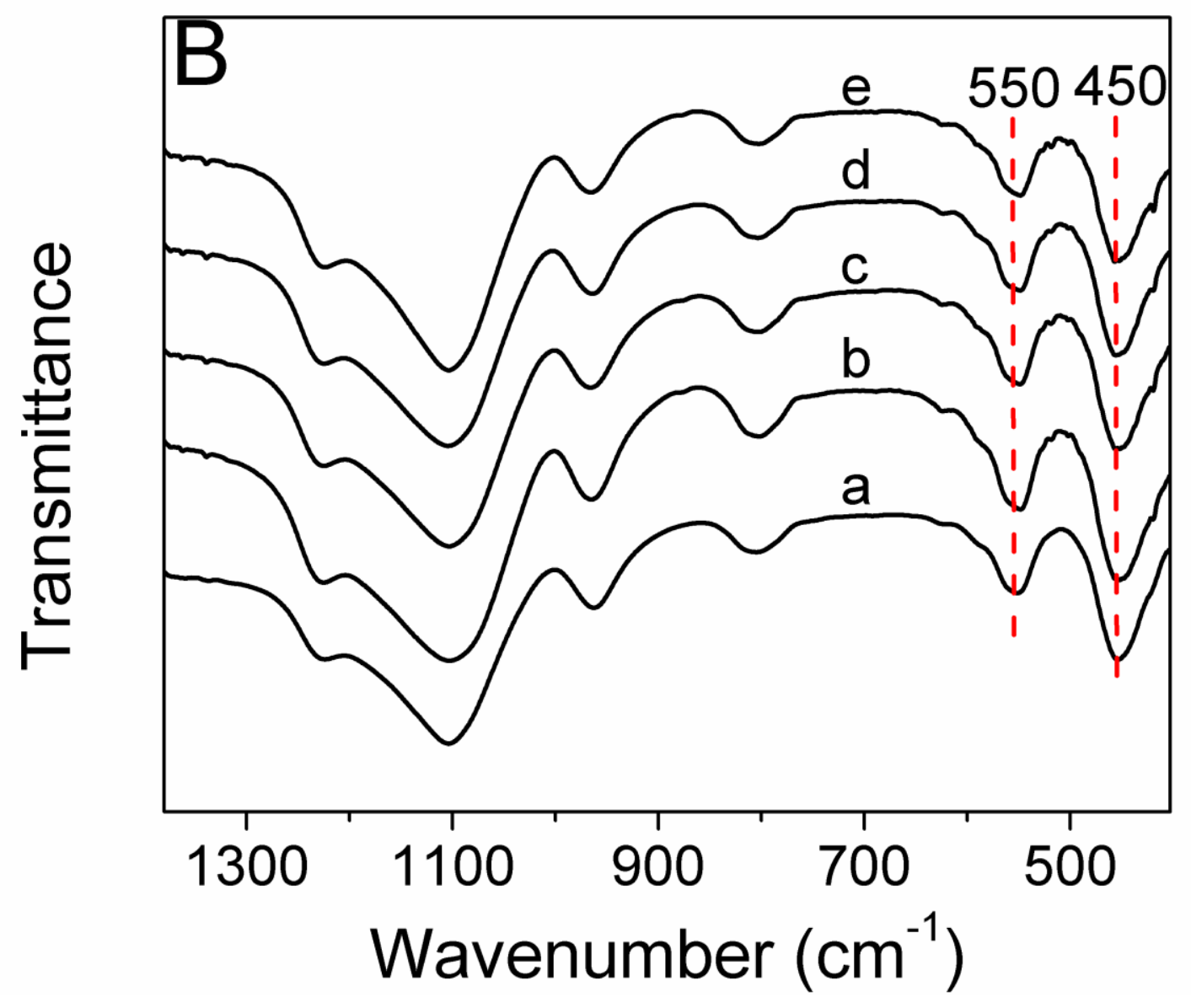




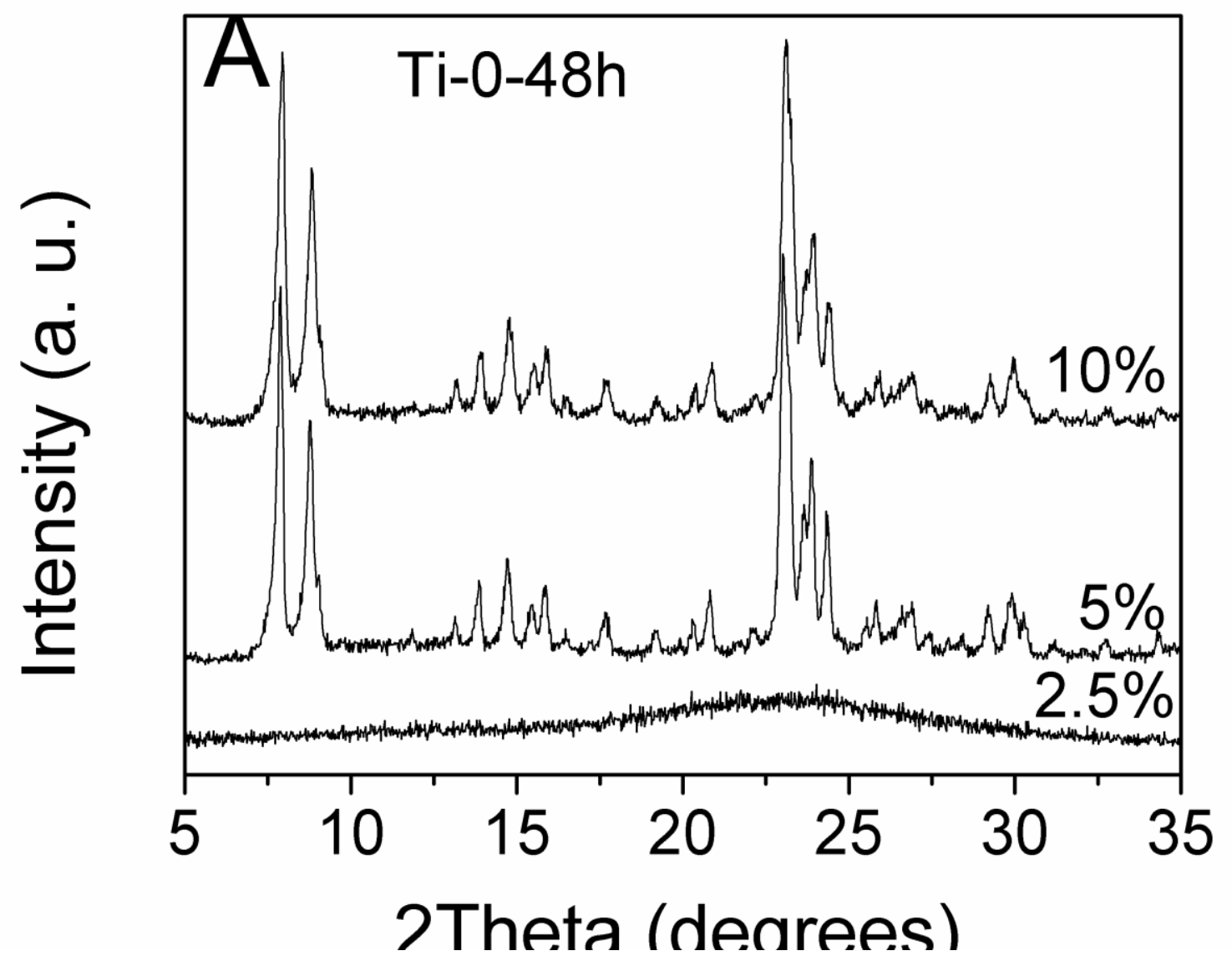




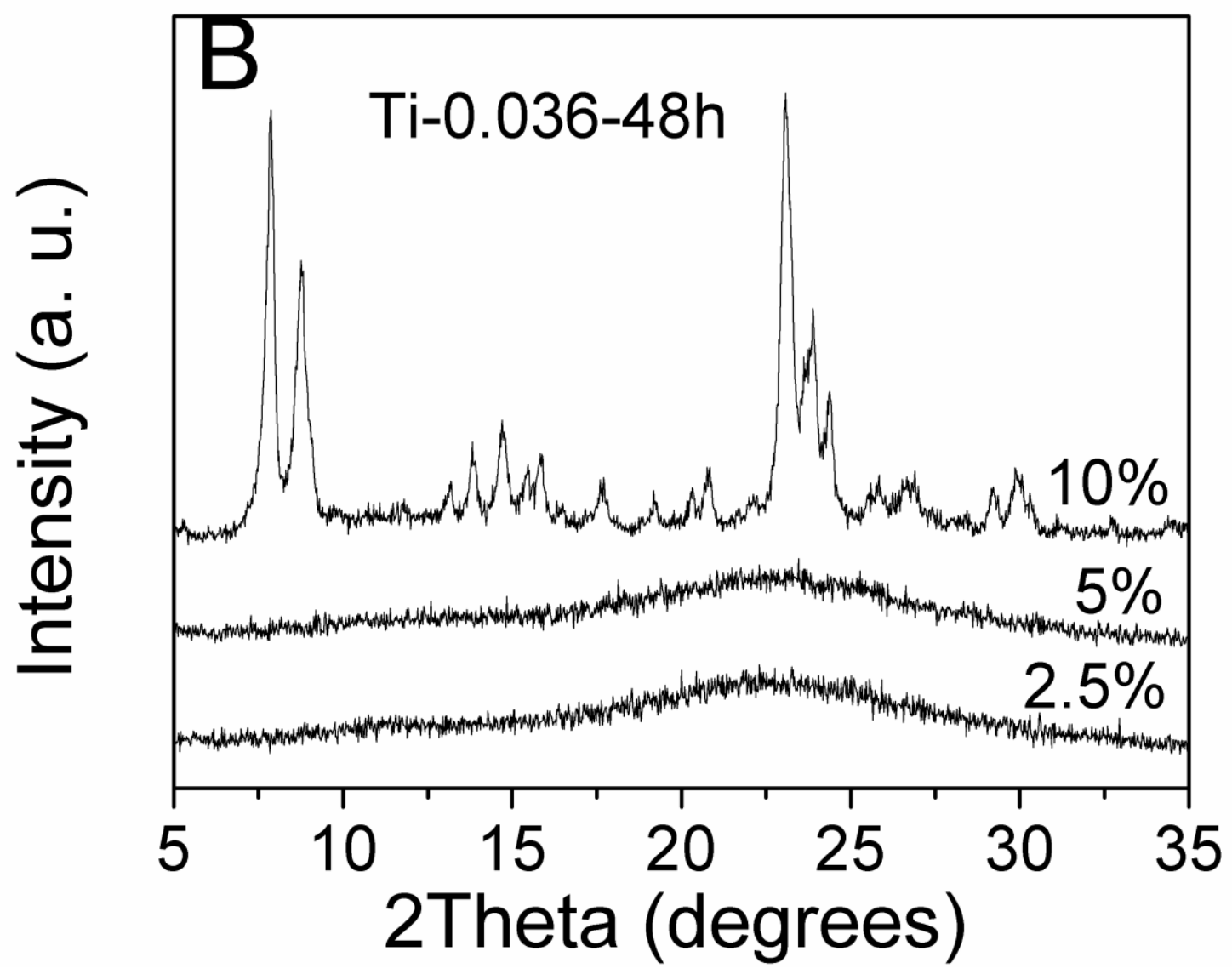




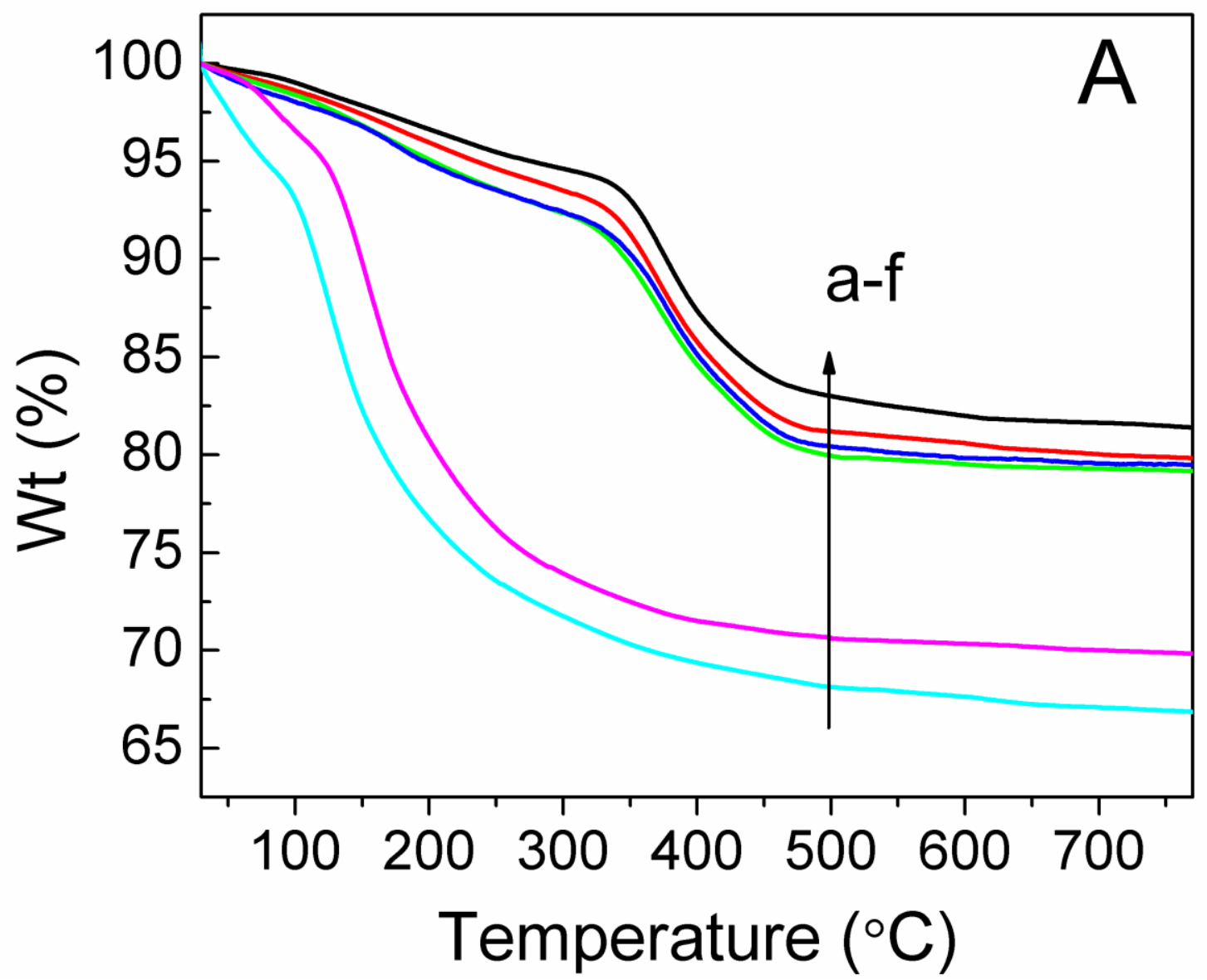




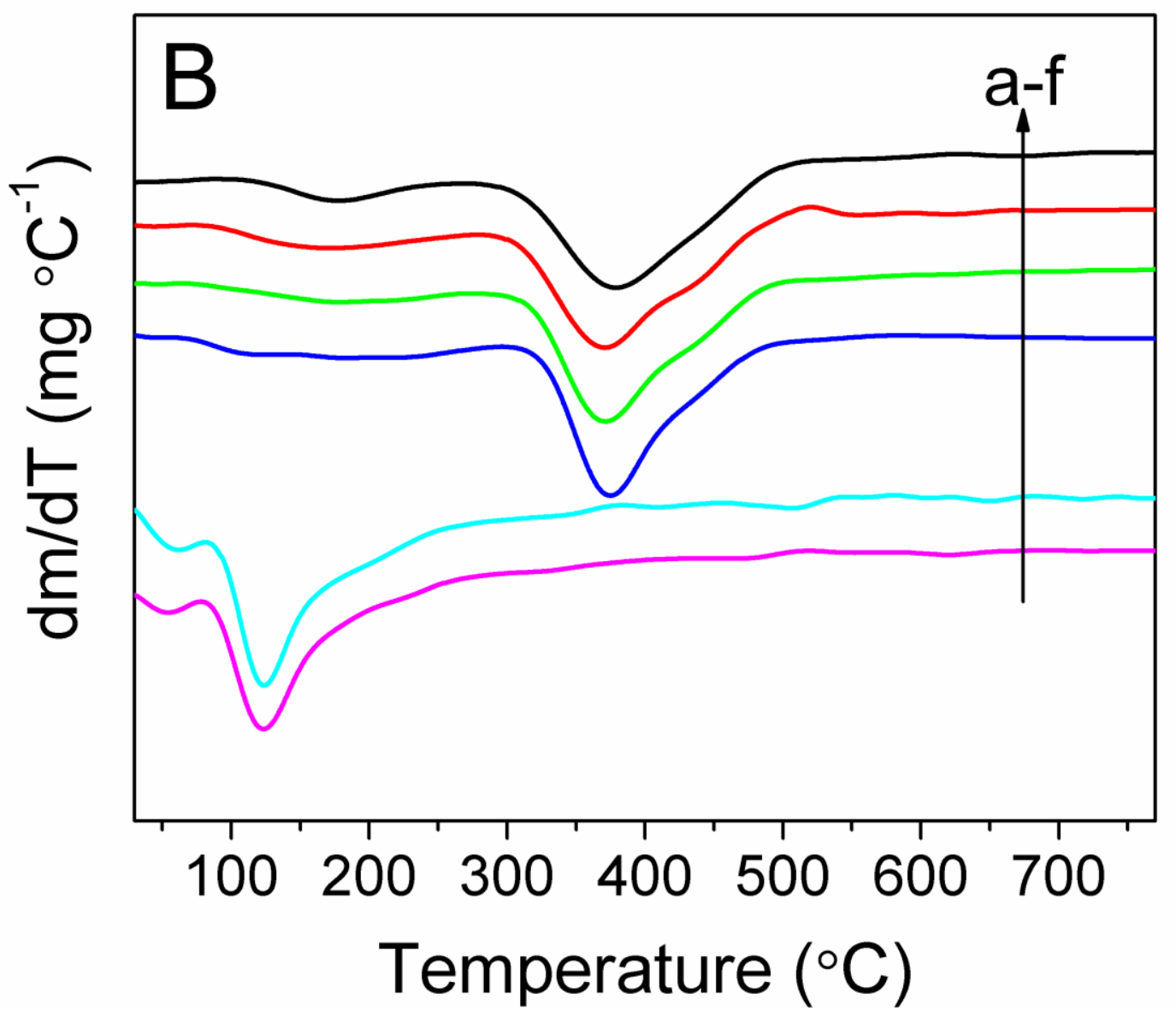




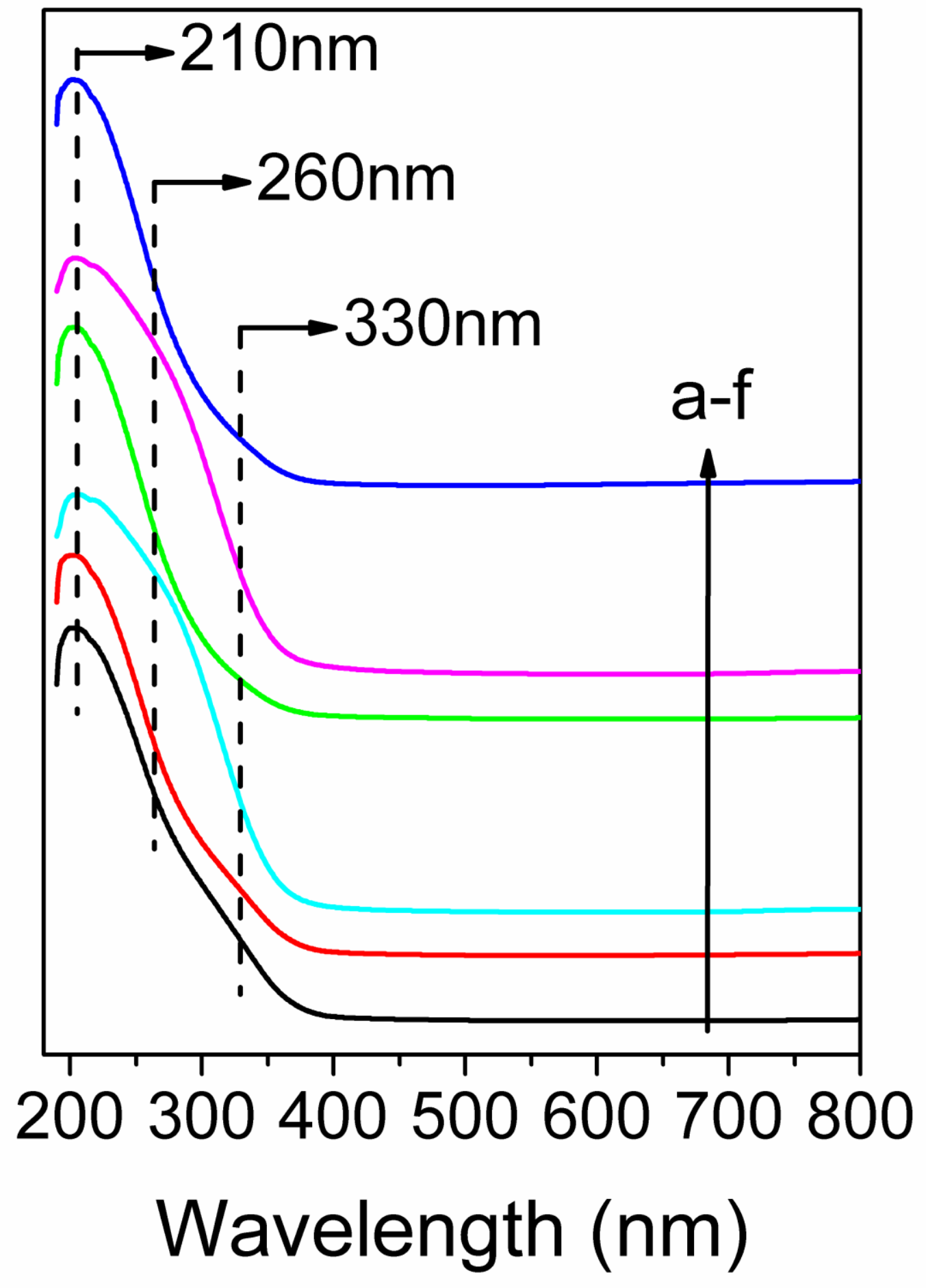




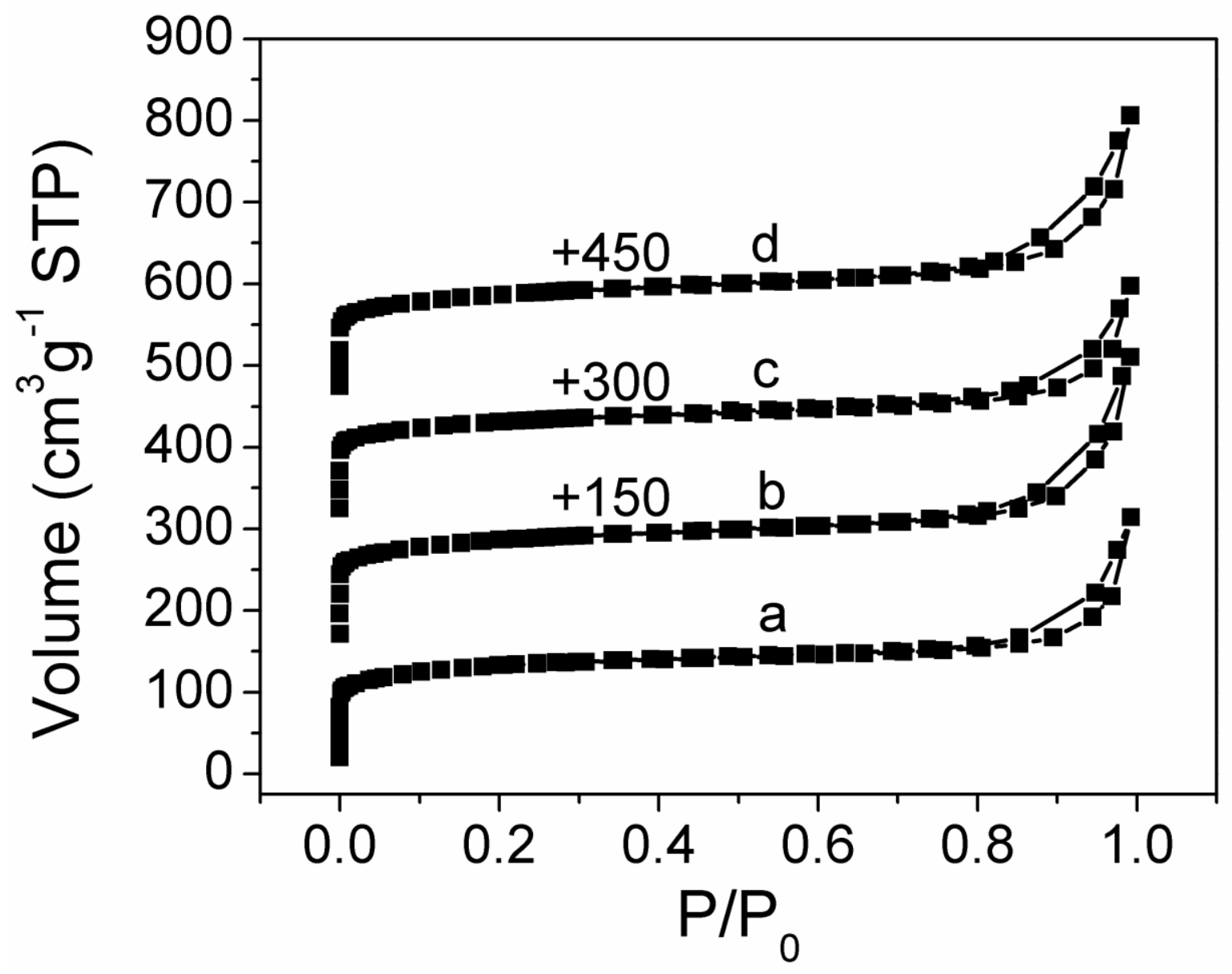




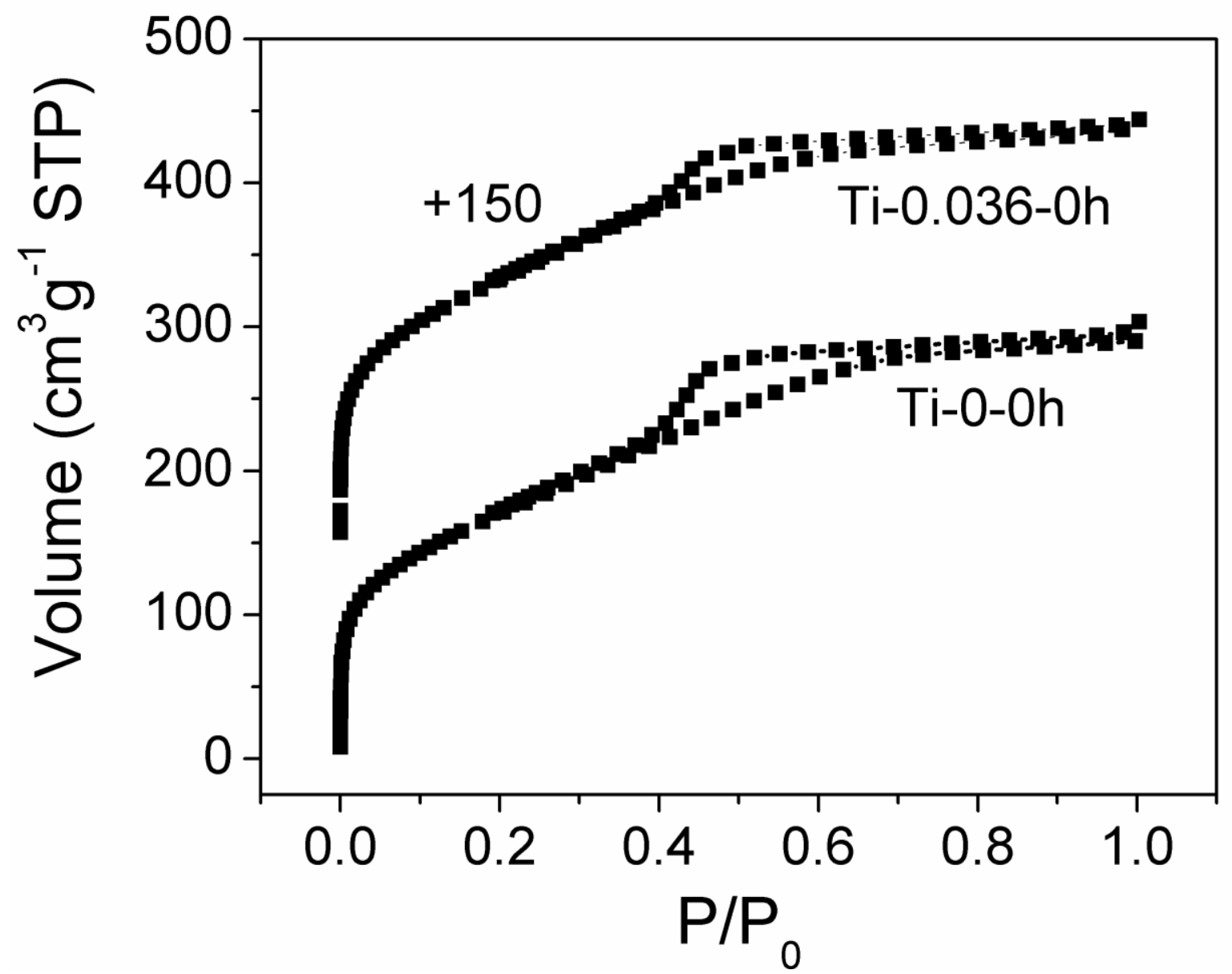



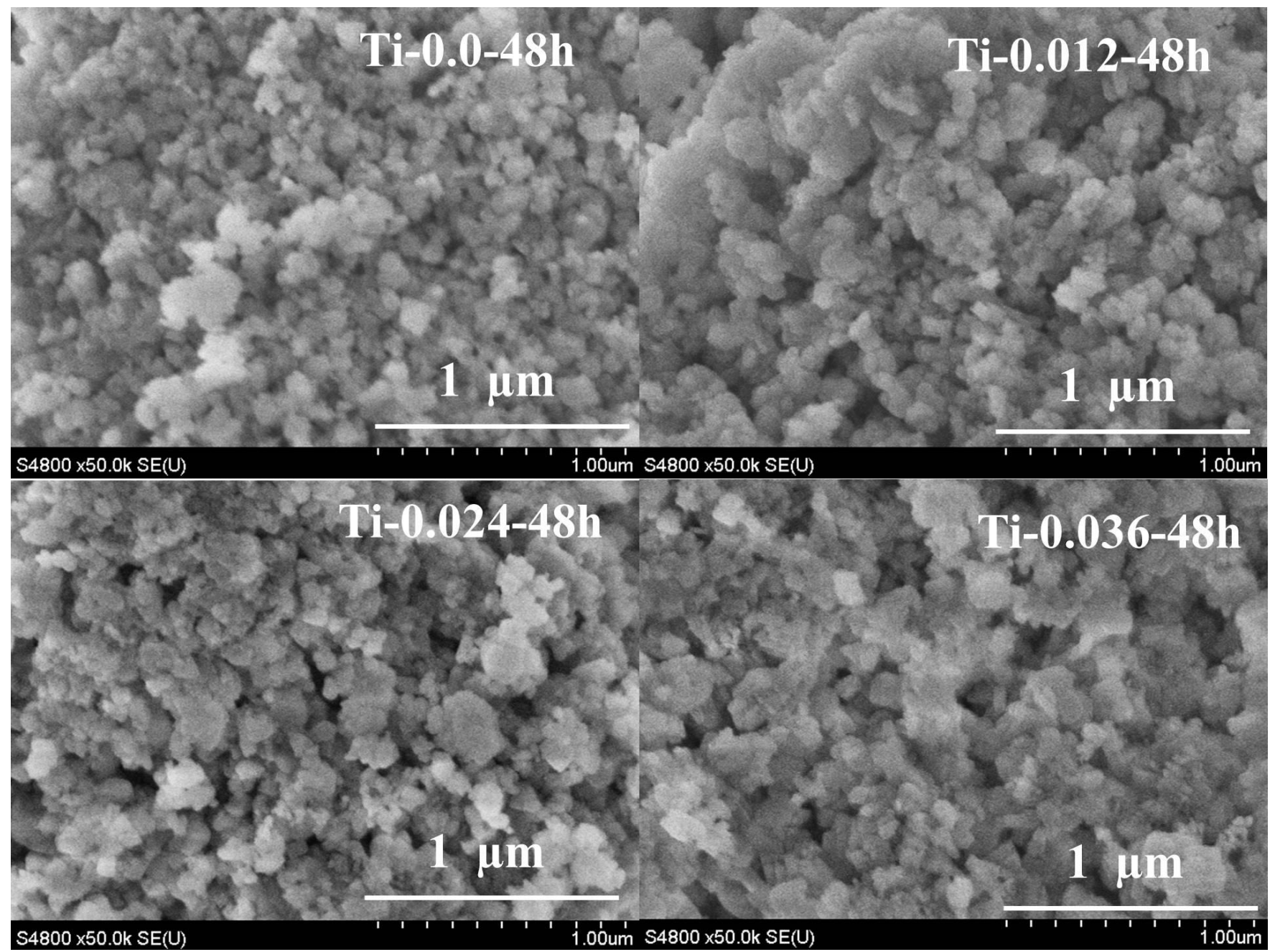


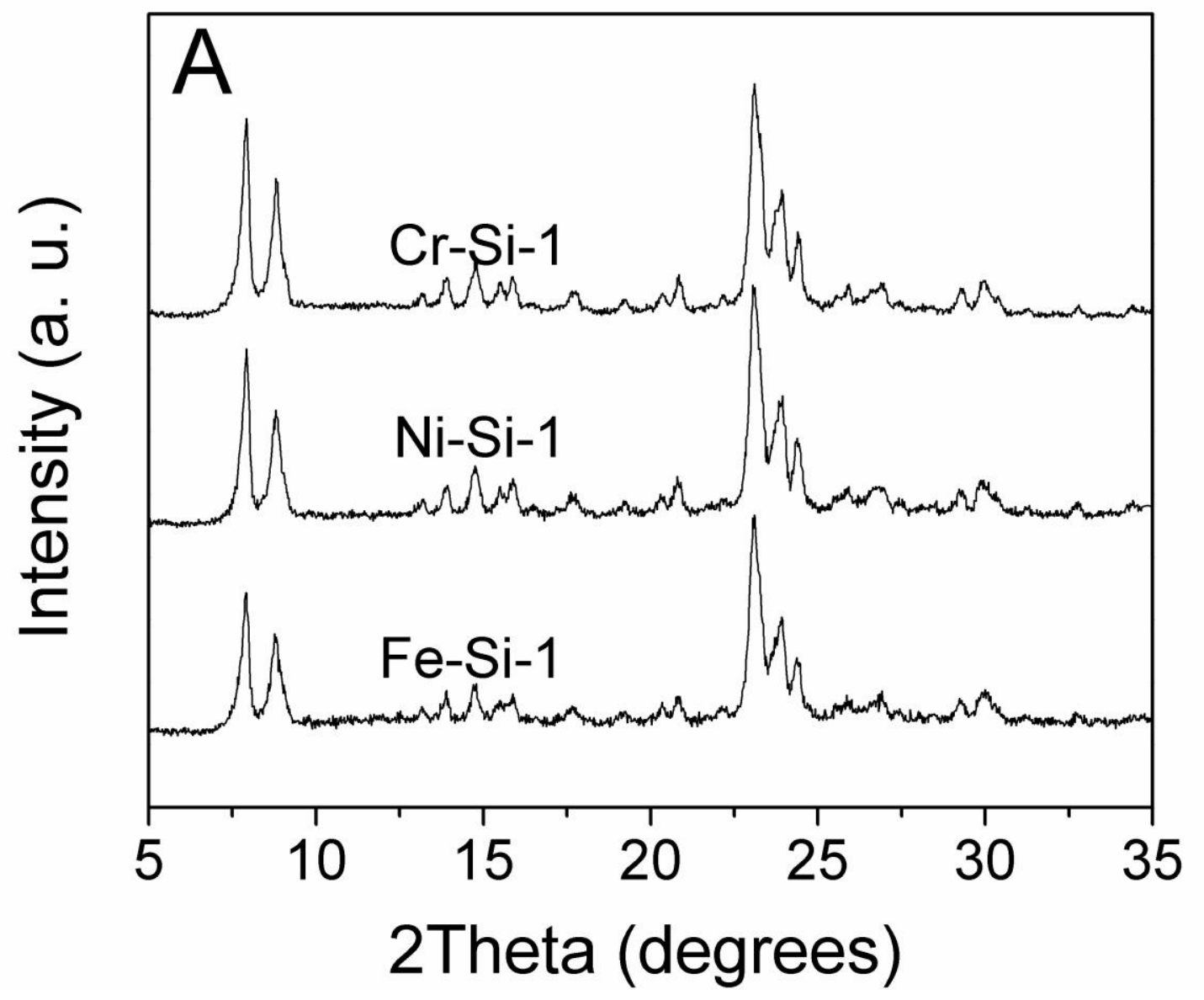




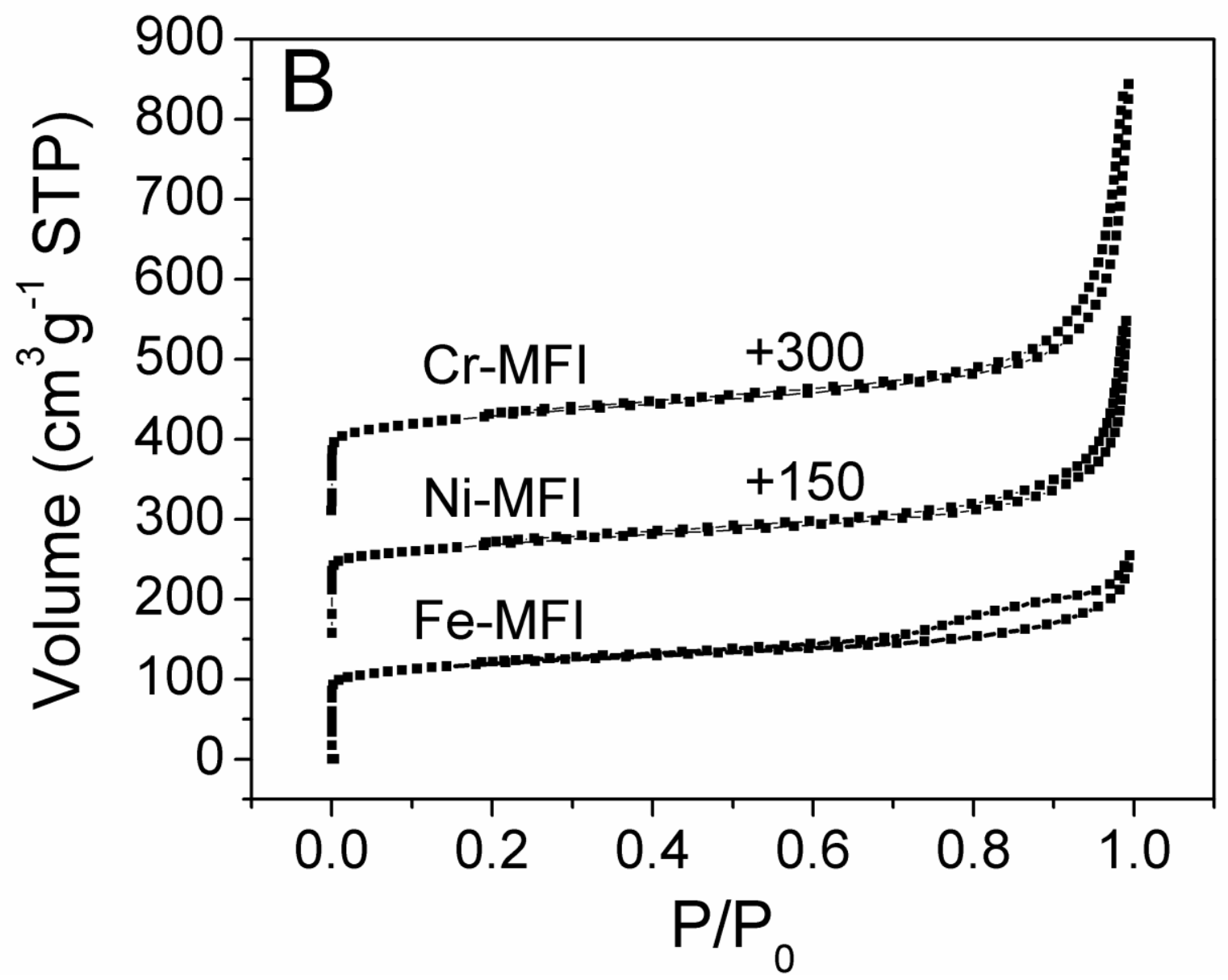




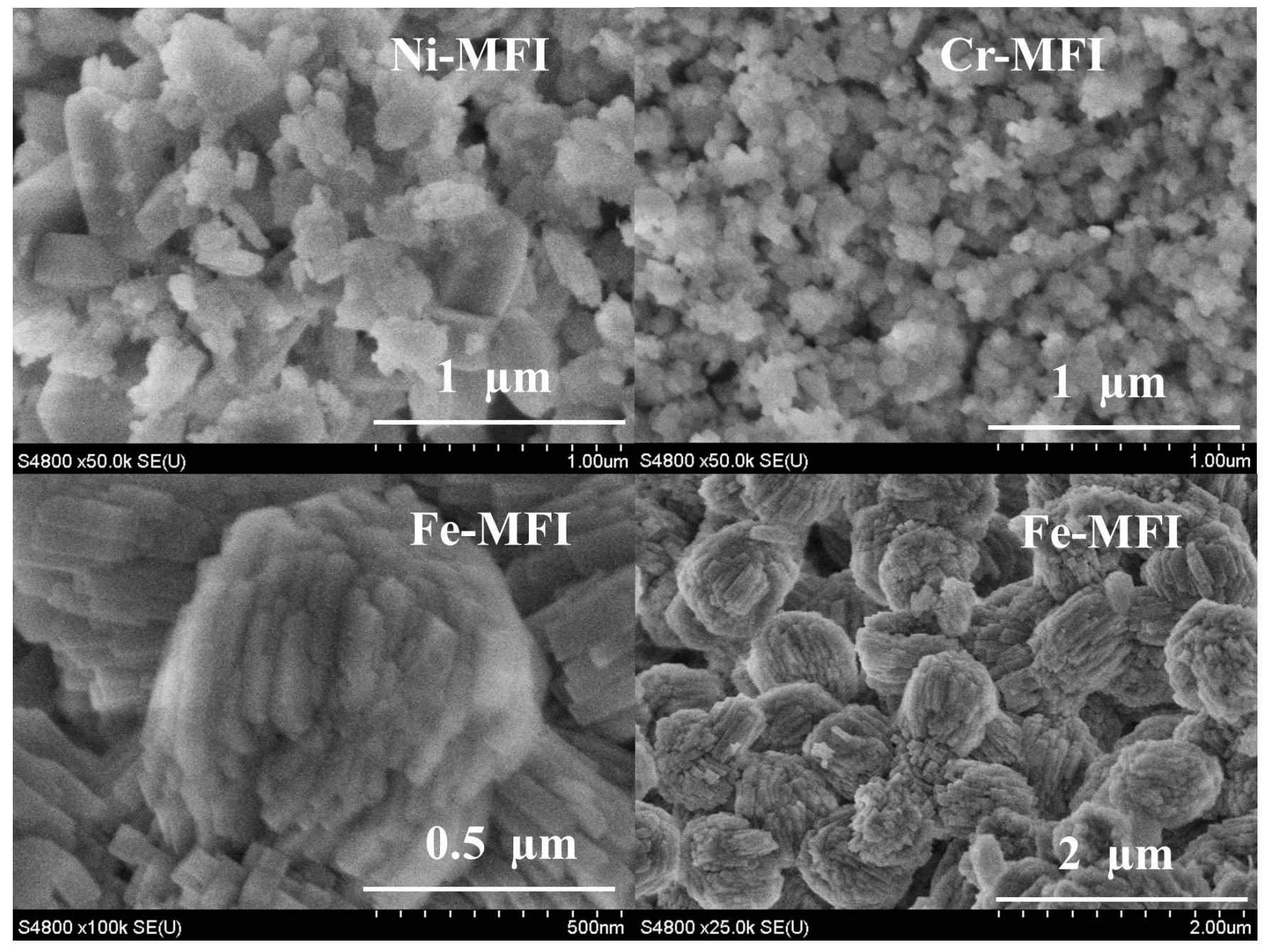




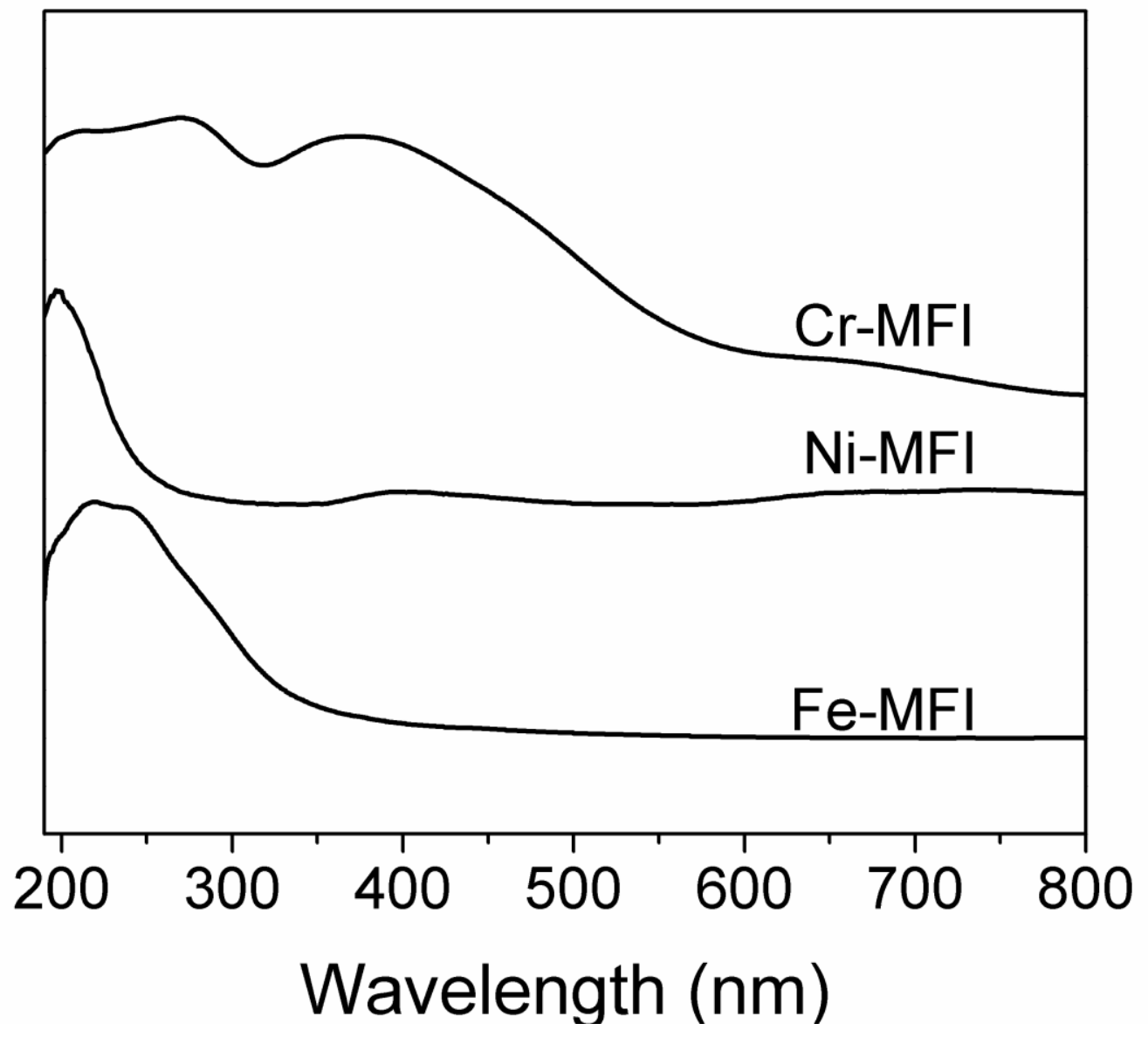




\section{Graphic Abstract}

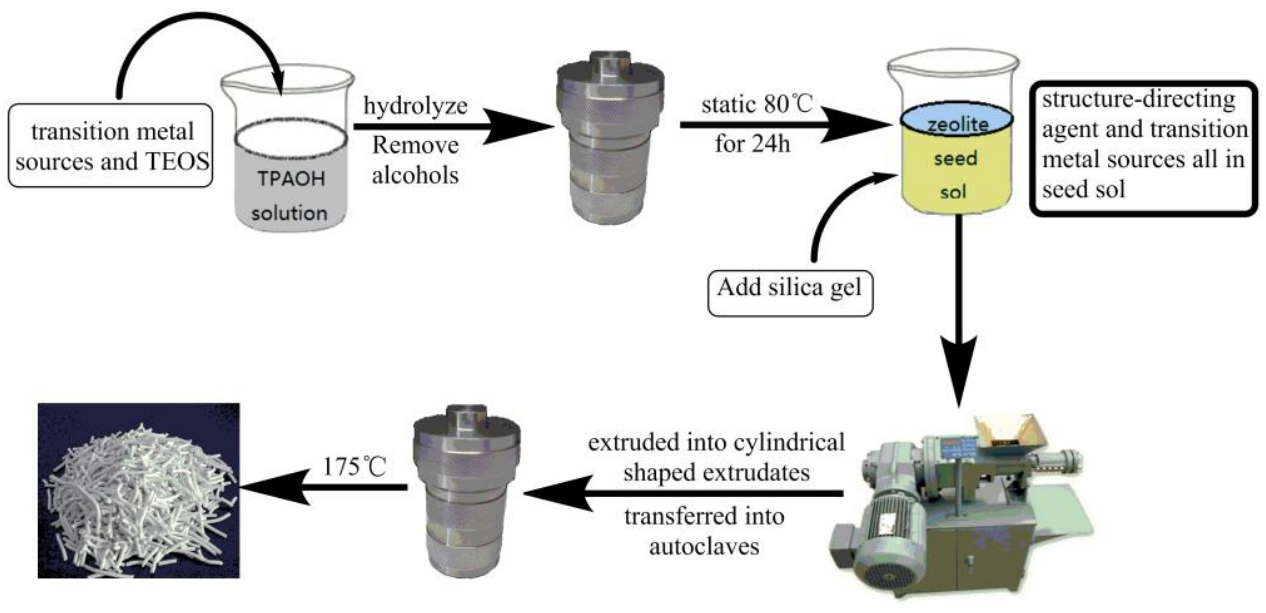

